\title{
Shadow Pandemic, An Inequitable Gender Violence during COVID-19: A Study Based on India
}

\section{OPEN ACCESS}

Manuscript ID:

ECO-2021-09033847

Volume: 9

Issue: 3

Month: June

Year: 2021

P-ISSN: 2319-961X

E-ISSN: 2582-0192

Received: 18.03.2021

Accepted: 24.04.2021

Published: 01.06.2021

Citation:

Arya, S., and B. Pradeep

Kumar. "Shadow

Pandemic, An Inequitable Gender Violence during COVID-19: A Study

Based on India." Shanlax International Journal of Economics, vol. 9, no. 3, 2021, pp. 1-4.

DOI:

https://doi.org/10.34293/ economics.v9i3.3847

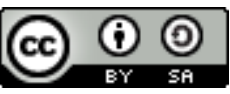

This work is licensed under a Creative Commons Attribution-ShareAlike 4.0 International License

\author{
S. Arya \\ Research Scholar, Department of Economics \\ University of Kerala, Thiruvananthapuram, Kerala, India \\ https://orcid.org/0000-0003-4124-467X
}

\section{B. Pradeep Kumar}

Head \& Assistant Professor, Department of Economics

Government Arts and Science College, Ambalappuzha, Alappuzha, Kerala, India

D https://orcid.org/0000-0003-4232-9640

\begin{abstract}
During COVID-19, gender-based violence has been intensified and women have to be confined to aggressiveness and harassment from their abusive partners. The lockdown prevents women from moving to a safer places to avoid sexual and physical violence. Continuous calls to the NGOs and concerned authorities seeking help and support since the outburst of COVID-19 justifies this observation. Disrupted public services and diversion of resources to COVID-19 pandemic relief inhibit women from rightness and justice. This situation has soup-up violence behind the doors that leads to shadow pandemic. In India National women's Commission reported a rise in registered domestic violence cases with the relaxation of lockdown, which points out the fact that a strong supporting system is necessary to ensure a high prior security system to women and girls all over the nation.
\end{abstract}

Keywords: Domestic violence, Women, Shadow pandemic, Lockdown, COVID-19, India

\section{Introduction}

During COVID-19, gender-based violence has been intensified and women have to be confined to aggressiveness and harassment from their abusive partners. In the world, one in three women experiences physical or sexual violence at any point in their life. It has heightened the risk of women and girls staying at home, and it has no longer safe. According to UN Women, globally, about 243 million women were subjected to physical and emotional exploitation last year. In between March and September, various NGOs reported that nearly $85 \%$ increase in harassment against women and this economic and security strain with violence experienced by women during COVID-19 leads to the term Shadow Pandemic.

Throughout the pandemic, several nations like the US, UK, France, China and India have verified and confessed that disrupted public services and diversion of resources to COVID-19 pandemic relief prevents women from having justice and this has soup up violence behind the doors. Finally, that leads to the silent pandemic of gender violence. The risk of violence from an intimate partner is likely to increase due to social distancing and home isolation (UN, Women, 2020). Following this, many community service organizations also demand that countries immediately adopt effective measures to challenge and address the domestic violence and savagery that occurred as a part of the lockdown. 


\section{Scope of the Study}

Humanity faces a great threat due to the international distribution of the epidemic Covid-19, which had originated from the Wuhan in China. All most every nation, are extremely affected by the numerous health-related and life-threatening impact of this particular pandemic. The World Health Organization and health experts and doctors advise people to be safe to raise awareness (Joshua Gans, 2020). In this situation, while focussing on retrieving this mishap, the government and other institutions fail to confront a leading issue, gender violence. A large section of women, without sufficient financial or family support, had been locked or even trapped within the house for a long period had been physically affronted by their abusive partner and close relatives after the declaration of lockdown. As per the data, married women always get abused by their husbands physically (27\%) and emotionally (13\%), which had aggravated during COVID-19 and after that lockdown. So more inquiries and inquests are necessary to spot the aggressiveness of gender violence and its impacts on womenfolk worldwide.

\section{COVID-19 and Gender Violence}

The COVID pandemic rides down the world into a state of physical distancing and isolation as time passes out, these circumstances being a part of life today. While the nations and society try to compete with the crisis by using all available resources and facilities, they forget to address the gender impact of disease outbreaks. The pandemic affected the women, who stay back without sufficient financial and mental support, deeply affected by social and economic inequalities within the system. The productive life of many women is seriously affected during the COVID-19 pandemic and they become stressed to balance career and family life.

Both men and women have lost their jobs during lockdown were seriously affected by frustration, poverty, deprivation and mug up to meet both ends. This leads to the alarming rise in the chances of women getting abused by partners and other household members. As per figures, married women always get abused by their husbands physically (27\%) and emotionally (13\%). At the same time, unmarried women face violence from close relatives like father, mother, stepfather, stepmother, brothers, etc. Generally, in developing nations like India, women face problems already due to lack of employment, limited education, negligible control over resources and gender exploitation, which adversely affected their self-respect and pride. The lockdown period multiplied the risk of harassment that women suffer that was neglected by the government and authorities where they use their all force and service to compete the COVID-19. In Indian families, male members usually try to abuse women physically and emotionally to hide their insecurities due to loss of jobs and continuous alcoholic use. During the lockdown, it seems to worsens and even be affected by violence and left shattered. Women at the same time reluctant to report this violence because they think that it is a private matter to conceal from society

As per the official data of the National Women Commission, domestic violence complaints increased by 2.5 times since the beginning of lockdown, which was a signal of a shadow pandemic. In 2019, the commission had registered 607 cases between march to May, while this case became 1474 . These complaints are received by NCW always from educated and upper-class sessions. In most cases, the victims do not have access to social media, the internet and cell phones, thereby keep themselves out of the mainstream of society. The UNFPA's recent report estimate that about 31 million additional domestic and gender violence cases can be expected if lockdown continuous for at least six months.

The NCW of India receives 13410 complaints of crimes against women from March 2020 to September 2020, 4350 were domestic violence. These complaints surged from March to May, as previously said where people are under complete nationwide lockdown. Ravindran and Shah (2020) said that in May 2020, the increase in domestic violence complaints in red zone districts was $131 \%$ higher than green zone districts which figure out that staying at home is no longer secure for women. Reports also confirm only $14 \%$ of violence-affected women seek help which clears that data of registered cases are tip of iceberg. The rise in domestic violence cases during lockdown leads Government to revive a supporting system that ensures a high prior security system to women and girls with specific efforts. 
Globally, WHO commenced INSPIRE program, which consists of seven strategies to create awareness about domestic violence and to achieve sustainable development goals like women empowerment and ending violence against children. They also launched another initiative known as RESPECT which provides guidance to prevent violence and assaults against women. Various governments all over the world committed initiatives to tackle gender violence like revising the justice system, communication campaigns using mass media and provide shelter and alternative accommodation for the survivors. Nations like Guatemala, India, Spain, France, and South Africa have supported victims to reveal their conditions with color-coded flags and wordless signs. Some nations increased their funding for anti-domestic violence services. Governments commended the postal workers and delivery staff to detect and report the abuse and crimes to the concerned authority. Through these all efforts, nations try to combat the rise in violence and harassment towards women.

In India, Government has passed the Protection of Woman from domestic Act in 2006 to tackle physical, sexual, mental, economic and emotional assaults against women from abusive partners, to protect their interest and freedom in society. During a lockdown, the situation becomes worse and worse for women. The nation has witnessed a surge in the registered complaints from women during a lockdown. To overtake this, Government adopts various initiatives to protect women from being exploited and raise awareness among them to react against the violence they face in their life. The authorities used many community organizations and mass media to convey their messages. The ministry of women and Child development recognized the need of a quick response mechanism to protect victims of domestic violence and they made arrangements for legal and psychological support.

National Commission for women has launched Whatsapp helpline numbers and complaint portals to report domestic violence cases on an emergency basis and appointed a special team to handle these cases to provide immediate care and security to the victims. They also telecast the messages to inform women and other marginal communities about these means.
Authorities also released a video on Psychological wellbeing Strategy to dealing with stress and distress women experienced during the lockdown. This video advises women to deal with the current condition and recommends various techniques to remain positive and productive. During a lockdown, this special media campaign by the commission has helped many women be aware of legal provisions for their protection and encourage them to approach the authorities to reveal their issues fearlessly.

Respective states have taken their safety measures to deal with this condition and try to ensure the safety of marginalized inmates suffers from harassment. In Odisha, police started to review previous cases of domestic violence and try to assure the current status of victims. Women Entrepreneurs for transformation WEFT started a campaign known as Red dot, where people can identify and inform authorities about domestic violence through the red dot on the palm. In Kerala, govt opened an online Adalat to resolve complaints related to domestic violence at the behest of the Conflict Resolution center. Other NGOs and service providers help to detect the violence and report it to concerned authorities.

\section{Conclusion}

The COVID-19 have shattered the social and economic stability of the whole world. While the government tries to fight against the pandemic with the help of policies and plans, they failed to support women and children from violence and assaults. Their problem is immersed in the discussion of a pandemic. Many of the victims cannot reveal themselves and afraid to report domestic violence because of financial dependence and fear of being stigmatized. The goal of sustainable development cannot be attained unless we irradiate violence against women and children. Education, employment and self-awareness are those means to empower women and preparing them to resist atrocities based on gender. The state should ensure grassroots level support to the women's community and self-help organizations, while reconsidering their role in addressing crimes against women and girls. So, effective social awareness, safe shelters, more sensitive and responding policies required by the government are required to deal with shadow pandemic, 'the silent disaster.' 


\section{References}

Campbell, Andrew M. “An Increasing Risk of Family Violence during the Covid-19 Pandemic: Strengthening Community Collaborations to Save Lives." Forensic Science International Reports, vol. 2, 2020.

Choudary, Rakesh, et al. "Domestic Violence Against Women's in India: A Study." PANACEA International Research Journal, vol. 1, no. 2, 2014, pp. 49-55.

COVID-19 and Ending Violence against Women and Girls. UN Women, 2020.

"COVID-19: Implications for Business." McKinsey \& Company, https://www.mckinsey.com/ business-functions/risk/our-insights/covid19-implications-for-business

"COVID-19: Stopping the rise in Domestic Violence during Lockdown." News - European Parliament, 2020.

Davies, Guy, et al. "Shadow Pandemic: Domestic Abuse Reports Soar during Europe's Coronavirus Crisis." ABC News, 2021.

Declaration on the Elimination of Violence against Women. United Nations, 1993.

"Economic Impact of the COVID-19 Pandemic." Wikipedia, https://en.wikipedia.org/wiki/ Economic_impact_of_the_COVID-19 pandemicFord, Liz. "Shadow Pandemic of Violence against Women to be Tackled with \$25m UN Fund." The Guardian, 2020.

Gans, Joshua. Economics in the Age of COVID-19. The MIT Press, 2020.
Karlekar, Malavika. "Domestic Violence." Economic and Political weekly, vol. 33, no. 27, 1998.

Kumar, Pradeep, and Tushar Kant. The Economic Impact of COVID 19 with Special Reference to India. 2020.

Maharajan, A., and O. Madhurima. Family Violence and Abuse in India. Deep and Deep Publication, 1989.

National Commission for Women, http://ncw.nic.in.

Nikore, Mitali. "With Covid-19, comes the "Shadow Pandemic": How the Surge of Domestic Violence gripped India's Women in 2020." The Times of India, 2020.

Rama Devi, T. "Gender Equality: Women Empowerment." Global Journal for Research Analysis, vol. 6, no. 9, 2017, pp. 141-143.

Ravichandran, Prabhadevi, et al. "Shadow Pandemic: Domestic Violence and Child Abuse during covid-19 Lockdown in India." International Journal of Research in Medical Sciences, vol. 8, no. 8, 2020, pp. 3118-3121.

Sahoo, Harihar, and M.R. Pradhan. "Domestic Violence in India: An Empirical Analysis." Man in India, vol. 89, no. 3, 2009.

Sujatha, D. "Redefining Domestic Violence: Experiences of Dalit Women." Economic and Political Weekly, vol. 49, no. 47, 2014.

"Using 'red dot' Signal, Women seek help to Escape Domestic Violence during Lockdown." Deccan Herald, 2020.

\section{Author Details}

S. Arya, Research Scholar, Department of Economics, University of Kerala, Thiruvananthapuram, Kerala, India, Email ID: aryasatheesh93@gmail.com

Dr. B. Pradeep Kumar, Head \& Assistant Professor, Department of Economics, Government Arts and Science College, Ambalappuzha, Alappuzha, Kerala, India, Email ID: pradeepgck@gmail.com 